Chapter 2

\title{
Endoplasmic Reticulum Stress in the Endothelium: A Contribution to Athero-Susceptibility
}

\author{
Alessandra Stacchiotti, Gaia Favero and Rita Rezzani \\ Additional information is available at the end of the chapter \\ http://dx.doi.org/10.5772/53024
}

\section{Introduction}

Currently the onset and progression of atherosclerosis have been established as the result of different cellular and molecular alterations that are not inevitable but rather predictable and so modifiable, if recognized on time [1,2].

From a morphologic point of view the vascular wall (common to each artery, vein or capillary of blood and lymphatic circulation) is made by three layers or tunicae: the tunica intimastarting from the inner and containing the endothelium, directly facing blood; the tunica media-with longitudinally oriented layers of smooth muscle cells connected by elastic and collagen fibers, that change the thickness according to the vascular type and function; and the tunica adventitia- the most external layer, containing vasa vasorum, necessary to maintain high metabolic requirements in larger vessels and the source of endothelial progenitors in neovasculogenesis [3-5].

However in this complex and specialized architecture, the endothelium layer certainly represents the first sensor of hemodynamic stress [6] and the favorite target for atherogenic factors, like circulating inflammatory molecules, macrophages, lipoproteins (LDLs) and many drugs [7].

Therefore in this scenario it is necessary to update the knowledge on the endothelium, which is the main player in the initial step of atherogenesis, and its involvement in a pivotal biological mechanism, called endoplasmic reticulum (ER) stress, associated to cardiovascular damage and invalidating pathologies such as stroke, cardiac ischemia, chronic renal failure, macular degeneration and obesity [8-11].

In particular we elucidate here the importance of the ER stress in the artery wall, because it very recently has emerged as a novel event able to promote athero-susceptibility and hyper- 
tension both in animal models and in clinical patients [11,12]. Remarkably this event is early detectable in the endothelial cells [13], sometimes concurrent with other well-known atherogenic processes, like inflammation, oxidative damage and endothelial cell death.

Nevertheless considering the focal distribution of plaques and their cumulative progression during the whole lifespan [14], it is mandatory to consider the role of ER stress signaling in the circulatory bed, in order to maintain the proper ER function, so preventing or reducing the progression into irreversible cardiovascular dysfunctions, such as atherosclerosis, hypertension and ischemic heart disease [15-17].

We firmly believe that focusing integrated basic and applied research on ER stress in the artery tree and in the heart might open new avenues in the treatment and management of invalidating cardiovascular complications $[18,19]$.

\section{The endothelium and the endoplasmic reticulum homeostasis}

According to the most accredited theory that indicates inflammation as the first pathogenic mechanism of atherosclerosis, the endothelium is really the crucial target of circulating molecules or cells and constitutes the main entrance for LDL during the initial step of asymptomatic artery wall changes that end into plaques or atheromata and their dramatic clinical evolution [20-23].

Recent studies have outlined that in atherosusceptible sites in the artery tree, endothelial cells acquire a proinflammatory phenotype which is permissive in the plaque development by expressing pro-inflammatory sensors such as Toll-like receptors (TLRs), that in turn attract leukocytes adhesion in the intima layer. Mainly TLR 2 and TLR4 are active in mouse in the progression of atherosclerosis and their signals stimulate a downstream adaptor molecule, called Toll/IL-1 receptor domain-related adaptor protein that induces interferon or TRIF. Indeed also in human vascular tree, by immunostaining and mRNA survey TLR2 and TLR4 have been well characterized in selected sites, including the aorta, subclavia, carotid, mesenteric, iliac and temporal arteries [24].

Nevertheless an important concept to remind here is that the relationship between the vascular endothelium and the blood is not only "passive" in receiving inflammatory or metabolic stimuli, but instead "active", with pleiotropic activities like the secretion of regulatory factors for cholesterol and lipid homeostasis, platelets recruitment, and the adaptation to local changes of blood flow and pressure $[25,26]$.

Moreover the artery wall, in particular in healthy resistance arteries, is not a static but a dynamic and plastic structure, able to remodel its diameter and structure, adapting to rapid changes in the systemic pressure [27].

Indeed also artery geometry directly influences the athero-susceptibility and the distribution of mechanical forces associated to blood flux, that impair the endothelium $[25,28,29]$.

In particular during unstable hemodynamic flux and changes in blood direction, mainly in arterial branches and bifurcations, it is particularly evident the heterogeneity of endothelial 
phenotypes that change their common flat shape and assume a polygonal morphology together with a different turnover. These events are linked to the susceptibility of a specific vessel to develop atherosclerosis and to the onset of valve calcification in the heart [30-32].

So endothelial dysfunctions may have serious consequences and a direct impact on the endothelial cells' role and activities, mainly on the resistance to dangerous stimuli that promote the onset of pro-atherogenic vascular damage recently reviewed by [33].

Indeed they involve different structural and functional aspects of the endothelium, that is classified as a monocellular squamous type of epithelium [34], lining human vascular and lymphatic tree, poorly detectable by traditional light microscopy but well characterized by electron microscopy and related techniques [35-37].

Nevertheless the real consideration of the endothelium by physicians has begun about 50 years ago, but only in the last decade, it has obtained more importance in the cardiovascular community, with the rediscovery of Weibel-Palade bodies and caveole signals, the role of transcytosis mechanism, and the active participation into vascular permeability [38-40].

Among most critical structural changes linked to endothelial dysfunctions, there are the reduction of glycocalix, which is the external component necessary to react against toxic apoB LDL, and the over-development of fundamental organelles like Golgi complex and the ER [41,42].

Remarkably the ER signaling in the vascular wall is the main topic of this chapter, because much more attention must be given to ER homeostasis in atheroprone sites in the artery tree, resulting from a chronic adaptive reaction to flow disturbance, concurrent with oxidative damage and inflammation $[43,44]$.

Abnormal ER activity has been recently reported in coronary arteries during altered hemodynamic changes, diagnosed by genetic techniques as an abnormal transcription of selected genes; while, in contrast, the transcriptional activity is lacking in more resistant arterial beds $[45,46]$.

Remarkably it must be pointed out that, in mammalian epithelial cells, the ER is commonly depicted by ultrastructural analysis as a perinuclear network of tubules and membranes, and by tomography as a dynamic assembly of tridimensional stacks associated to mitochondria [47-49].

Moreover it is well-known that the ER has different specialization and structure, called rough or smooth, if associated or not to ribosomes in the same cell, but in specialized cardiac and smooth muscle cells in the vascular wall it is called the sarcoplasmic reticulum $[50,51]$.

Anyway, this dynamic organelle represents the elective site where nascent polypeptide chains are gradually converted in a stable tertiary structure, that is associated to a specific protein [52].

Among the main ER functions have been comprised the folding of neo-synthesized secretory and trans-membrane proteins, the regulation of calcium balance and the synthesis of lipids, like steroids and cholesterol [53]. 
If one of these activities fails, the ER efficiency is lost and aberrant unfolded proteins accumulate within the ER membranes, causing the "ER stress". This condition has been defined as " any perturbation that compromises the protein folding functionality" in the organelle and implies an adaptive response to restore correct ER homeostasis [54,55].

So it has become clear that each perturbation in the ER balance interferes with folding process of different proteins, that are devoid of their intrinsic function, so unable to properly work in the cells and often degraded by a process called ER associated degradation (ERAD) [56-58].

In mammalian cells, disrupted ER homeostasis can be restored within short or long time according to the type of stimulus, if acute and transient or chronic and prolonged.

It is accepted that endothelial cells may tolerate acute stressors that last short time, such as circulatory ischemia or hypoxia, calcium and nutrient deprivation, adapting themselves to clear dysfunctional proteins. In doing this activity, they use a rapid process that involves a transient intracellular signaling from the ER to the nuclear transcription mechanism of genes, called "unfolded protein response" or UPR [59-62]. Indeed UPR is able to rectify and limit the cellular damage induced by metabolic, genetic, environmental factors, enhancing cell survival, but strictly related to the duration of the stress. On the contrary, if the stressful stimuli are severe or last for a long time, like the majority of chronic inflammatory and hemodynamic factors in atherogenesis, UPR is unable to resolve persistent ER stress so leading to endothelial cell death, generally by apoptosis (Figure 1).

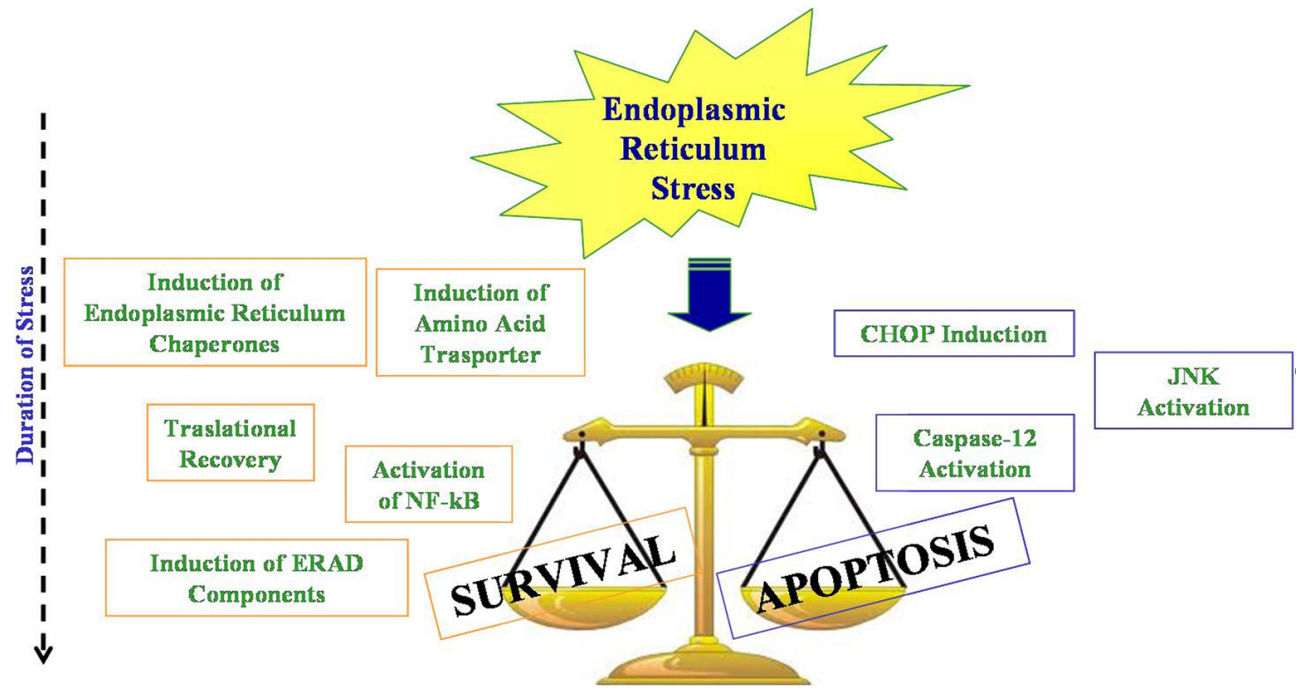

Figure 1. ER stress balance - Schematic representation of ER homeostasis: on the left, adaptive responses to acute stress that lead to recovery and on the right, reactions to chronic vascular stress that lead to apoptosis. NF-kB-Nuclear Factor k-B; ERAD-ER-associated degradation; CHOP- C/EBP homologous protein; JNK- c JUN NH2-terminal kinase. Adapted by [63]. 


\section{ER stress and UPR pathways in cardiovascular diseases}

Given the vital role of fundamental UPR to augment the protein folding in the ER and to reduce the pool of misfolded products, it is clear that this organelle represents an efficient checkpoint for quality control of secretory proteins that may migrate to other organelles and/or to the plasma membrane to be secreted. Indeed UPR works also in collaboration with the Golgi apparatus and plasma membrane, and only correctly-assembled molecules are driven to their final destination. Therefore the kinetic and the amplitude of UPR are emerging as key events for combine a stress response in specific cell types to their final fate and eventually death [64].

In the heart, for example, the UPR pathway produces several proteins, that ameliorate the ER ability to cope with stress, by three separate mechanisms: 1) translational attenuation, that avoids further deposition of abnormal proteins in the ER; 2) transcriptional activation of genes for chaperones and related proteins [65];3) activation of a process to hamper the further deposition of dysfunctional proteins called ERAD [11].

Indeed to start the quality control work in the ER factory, it is crucial that about one-third of novel proteins are translocated there, because they acquire the specific configuration and assembling with the assistance of ER chaperones, then further change by post-translational modifications, like disulphide bonds or glycosylation performed by specialized enzymes $[66,67]$.

Remarkably unlike the cytosol, where the abnormal accumulation of proteins is handled by different families of chaperones, belonging to heat shock protein (HSP) 20 and HSP70 families, called HSP25/27 and HSP70 [68,69], in the ER environment the UPR mechanism is sustained by specific resident chaperones, glucose-regulated protein (GRP) GRP78 /Bip, GRP94 and by lectin chaperones calnexin, calreticulin and calmegin [70,71].

In eukaryotic cells GRP78, a trans-membrane protein, is called "the master regulator" of ER stress response and usually works by binding to nascent polypeptides to ensure their proper secondary structure. In unstressed conditions, GRP78 is usually associated to three different UPR-sensors and renders them inactive through the direct interaction with their N-terminus [72]. In contrast, when unfolded proteins accumulate in the ER, GRP78 dissociates from three UPR-sensing elements, and allows their oligomerization and activation, so ensuring the start of the UPR cascade.

Currently, it is established that GRP78 is induced by chemical and inflammatory atherogenic factors, further associated to ER stress signaling, such as excess cholesterol, oxidized phospholipids, peroxynitrite, homocysteine $[73,74]$. In a recent in vitro model, that simulates human arterial shear stress waveforms, GRP78 was over-expressed in the endothelial cells as a compensatory effect before lesion development [75]. The mechanisms by which GRP78 increased were dependent on upstream alpha 2-beta1integrin linked to p38 activity localized to focal adhesion in the endothelial cells upon long-term shear stress [76].

Remarkably in the above study it was further demonstrated that inflammatory cytokines associated to atheroprone environment, had no effect on GRP78 expression in the endothelial 
cells. So it is plausible that hemodynamic flow might be the earliest ER stressor and GRP78 inducer in an atheroprone environment.

Moreover the conservative pro-survival role of GRP78 is outlined also in vivo, considering that GRP78-deficient mice are embryonic lethal and present increased apoptosis [77].

The canonical UPR starting signals include three distinct pathways: the inositol-requiring kinase 1 (IRE1), the transcriptional factor activating transcription factor 6 (ATF6) and the protein kinase-like ER kinase (PERK) [15] (Figure 2).

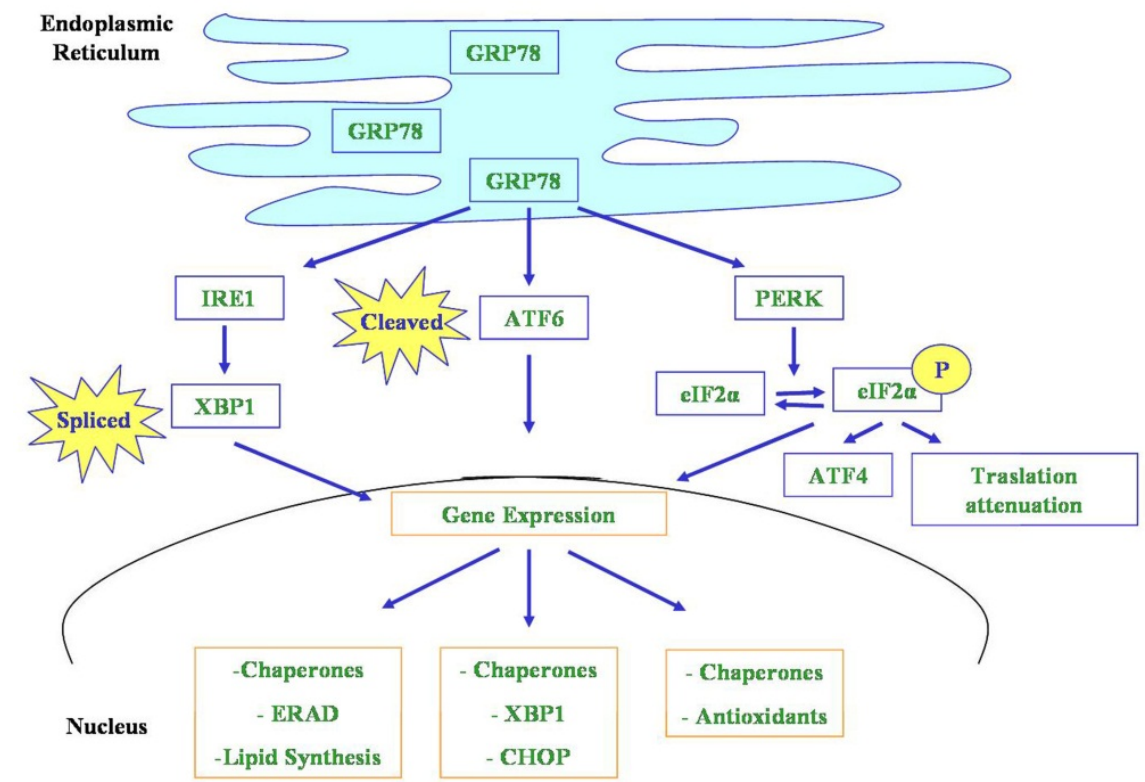

Figure 2. Canonical UPR pathways. IRE1-inositol-requiring kinase 1; ATF6- ATF4- activating transcription factors 6 or 4; XBP1- x-box binding protein 1; elF2alpha- initiation factor 2 alpha; ERAD- ER-associated protein degradation pathway; GRP78- glucose-regulated protein; PERK- protein kinase-like ER kinase; CHOP- C/EBP homologous protein. Modified from $[15,78]$.

This last enzyme is able to phosphorylate the translation initiation factor 2 alpha (eIF2alpha) after ER stress then reduces the further protein load on the ER by blocking mRNA translation. In contrast, there are some mRNAs that require eIF2 alpha autophosphorylation for their translation, including the transcriptional factor ATF4, that is directly involved in the nuclear activation of UPR-related genes. Furthermore eIF2 alpha influences, by endonuclease activity, the splicing of another transcriptional factor, called X-box binding protein 1 (XBP1), that regulates the transcription of UPR-related genes, although in the heart its function is largely unknown [79].

ATF6 is another crucial transcriptional factor that, moving from the Golgi complex, becomes activated and able to interact with XBP1 target genes for the synthesis of molecular chaper- 
ones and also for enzymes involved in the ER-associated protein degradation pathway (ERAD). The ERAD mechanism mediates the translocation of unfolded proteins from the ER into the cytosol where they are degraded by the ubiquitin-proteasome system and so alleviates the ER over-crowding [58].

Interestingly, a novel gene, called derlin-3, as a component of the ERAD induced by ATF6, was recently discovered in the mouse heart, and derlin- 3 over-expression was able to protect cardiomyocytes from ischemia-induced apoptosis in vitro [80].

Besides ER chaperones involvement, dysfunctional proteins may be degraded directly in the ER in a chaperone-independent manner, by a specialized protease system called the ubiquitin-proteasome, that works independently or in synergy with the UPR. According to recent clinical and experimental studies, atherosclerosis may be considered also as a "protein-quality disease" and the proteasome works at early phases of the disease, especially in both the coronary and carotid arteries, as a compensatory reaction to prevent complete protein dysfunction [81].

It is currently accepted that in mammalians the necessity to remove aberrant proteins that engulfed the ER environment is based upon three main ER activities: 1) the transient UPR associated to resident chaperones, 2) the ubiquitin-proteasome system and 3) the prolonged UPR linked to autophagy [82].

In particular through this last process, properly called macro-autophagy, abnormal cytoplasmic contents or organelles engulfed in autophagosomes, upon fusion with lysosomes, are degraded.

Evidence is emerging that the ER provides membrane for autophagosome formation and that autophagy is crucial for ER homeostasis due to its ability to remove unwanted or damaged organelles like abnormal mitochondria by mitophagy [83]. Moreover the ER contributes also lipids and specific proteins, such as beclin-1, to initiate autophagosome formation very close to itself. This physical proximity probably reflects a functional dependence between ER and autophagy process, that in the endothelial cells often occurs in response to reactive oxygen species (ROS) by circuits localized to the ER surface [84]. However in dividing cells with high turnover, autophagy may not be so relevant, but in long-lived cells like smooth muscle cells and cardiomyocytes, it is critical to maintain optimal cellular function.

Remarkably autophagy is a suitable mechanism to eliminate abnormal proteins and organelles, during fast and relatively mild ER stress conditions, but if the ER stress is severe, this mechanism is overwhelmed.

Anyway, many studies suggest that autophagy is activated in the heart and vascular tree as a defensive mechanism for survival during myocardial ischemia/reperfusion and in atherosclerosis $[85,86]$.

If autophagy may be considered as a safeguard that protects vascular wall from rupture-prone lesions, autophagy up-regulation by recent pharmacologic modulators has been proven to be effective in short-term experimental studies on knockout atherosclerotic mice [87]. Moreover autophagy is directly involved in the acute setting of cardiac diseases by providing metabolic 
substrates for producing energy and thiol repairing, so the regulation of the autophagic machinery may offer promising therapeutic opportunities to treat ischemia/reperfusion damage and heart hypertrophy $[88,89]$. Recently this interesting eventuality has been also demonstrated in experimental studies in genetic murine models, notably beclin 1(+/-) and Atg5 deficient mice, even if its application in clinical trials is still an hypothesis [90].

In this scenario it is intriguing the proposed role of macrophages, able to remove apoptotic cell debris in the advanced atherosclerotic plaque by a mechanism called efferocytosis. It is well-known the active role of these cells in the inflammatory cascade inside the vascular wall, where they enter as adherent monocytes then become macrophages and foam cells, according to the progression of atherosclerosis [91]. The efferocytosis process seems necessary to limit atherosclerosis, because only a selective fully-operative efferocytosis retards the progression of this inflammatory disease [92-94].

The apolipoprotein E (ApoE) family comprises crucial lipoproteins present in the blood to transport the cholesterol and also to modulate several metabolic diseases like atherosclerosis and Alzheimer's [95]. The human ApoE gene is composed by different isoforms with different metabolic properties and the most studied are apoE3 that is protective and apoE4 that, in contrast, accelerates atherosclerosis and coronary damage. A recent study demonstrated that peritoneal macrophages isolated from ApoE4 mice were defective in the efferocytosis mechanism and if stimulated by inflammatory molecules, such as oxidized lipoproteins (ox-LDLs), were sensitive to apoptosis throughout the abnormal intensification of ER stress pathway [96]. However the above condition was greatly ameliorated by chemical stimulation of ER signaling, that reduced inflammation linked to apoE4, and balanced ER stress response.

Anyway if the UPR involvement in pathological complications has been largely outlined, it is important to remind that this signaling is commonly evoked during the heart morphogenesis and in healthy physiological conditions [97].

Really the strict association between the UPR signaling and pathology has been reported since about 20 years ago, in different pioneering papers $[98,99]$ that discussed the relationship between dysfunctional ER and proteotoxicity, and its direct role in neurodegenerative conditions characterized by abnormal protein deposition, like Parkinson's and Alzheimer's diseases.

Seminal studies have then elucidated the crucial role of the disruption of the regular ER activity in several metabolic disorders like obesity, diabetes insipidus up to neurodegenerative diseases like Creuzfeld-Jacob, Hungtington's, Parkinson's [9,100]. Moreover this mechanism has been actually involved in the pathogenesis of chronic disorders, including cancer, liver diseases, heart failure and in particular atherosclerosis [101,102].

Interestingly ER sensing may contribute to atherogenic damage by four ways: 1) by connecting lipid metabolism and UPR; 2) by promoting abnormal glucose metabolism and insulin activation that serve as a bridge-mechanism between metabolic dysfunctions and atherosclerosis; 3 ) by driving macrophages cell death after cholesterol loading; 4) by controlling autoimmunity based on the processing and presentation of MHC-1 associated peptides. 
Currently there is ample evidence of the involvement of the immune system in the pathogenesis of atherosclerosis and ER stress-driven autoimmunity may represent a novel contributing factor in the progression of the disease [103,104].

\section{ER stress induced-cell death in the vascular wall}

A growing body of evidence indicates that prolonged ER stress, due to the persistent accumulation in the ER of misfolded proteins beyond the ability of transient UPR, causes cell death in the vascular wall and may contribute to the pathogenesis of atherosclerosis and other cardiovascular disorders, such as cardiac hypertrophy, and acute coronary syndrome [78,105-107].

Intriguingly, the three arms of UPR act together to resolve the prolonged ER stress but if they fail to reduce the amount of unfolded or misfolded proteins, an ER-driven pro-apoptotic signal starts.

The most common apoptosis-triggering molecule associated to UPR signaling is called C/EBP homologous protein, or CHOP, known also as GADD153 [108].

In the endothelial cells, different atherosclerotic-relevant UPR inducers have been identified in many in vitro and in vivo studies. In particular, the strict association between ER stress marker GRP78 and CHOP has been reported in patients and in coronary artery samples, mainly in thin-wall or ruptured plaques associated with unstable angina respect to stable plaques. Evident localization of two ER-stress signals was further correlated to mRNA expression by in situ hybridization in thin-walled plaques and results indicated a positive relationship between these markers and plaque vulnerability in human coronary arteries [109].

Among murine models, many studies have been performed in apolipoprotein E deficient mice $\left(\mathrm{ApoE}^{--/}\right)$, fed a standard chow diet that developed atherosclerosis during the life-span up to necrotic plaques [110]. In this murine model, ER stress markers such as GRP78 and CHOP are upregulated in macrophages at all stages of lesion development in the aortic root [111]. However it is important to remark that in the aorta of $\mathrm{ApoE}^{-/-}$mice at 9 weeks of age, corresponding to early atherosclerotic phase, no apoptosis was detected, but this event occurred in macrophages and foam cells in advanced lesions at 23 weeks of age. Remarkably strong GRP78-immunostaining was also localized in the fibrous cap surface in hyperhomocysteinemic ApoE ${ }^{-/}$[112]. Furthermore in transgenic CHOP-deficient mice less macrophages have been found in advanced atherogenic lesions, such as instable plaques, respect to wild-type mice.

Intriguingly in double knockout mice (CHOP and ApoE-deficient) the rupture of atherosclerotic plaques was significantly reduced despite their high-cholesterol diet [113]. Indeed also in primary cultured macrophages free cholesterol accumulated in the ER and stimulated apoptosis in a CHOP-dependent pathway, so CHOP probably contributed in vivo and in vitro to instability of plaques due to macrophage cell death. 
It is emerging that, in crucial artery wall sites, the IRE1 branch of the canonical UPR mechanism and its downstream CHOP signaling are activated also by various factors like disturbed blood flow and hypertension $[19,114,115]$ and modified LDL.

High level of XBP1 splicing was detected in atherosclerosis prone areas, and in a mouse isograft model mimicking XBP1 overexpression, peculiar signs of atherogenic damage have been detected, like neointima formation and monocytes infiltration [116].

In particular in the endothelium multiple UPR pathways are activated by phospholipolized LDL that stimulate ER stress associated to cytoskeleton stress fibers formation, inflammation and dysregulation of calcium homeostasis, even if strictly related to the intensity and duration of the lipidic stress [117] (Figure 3)

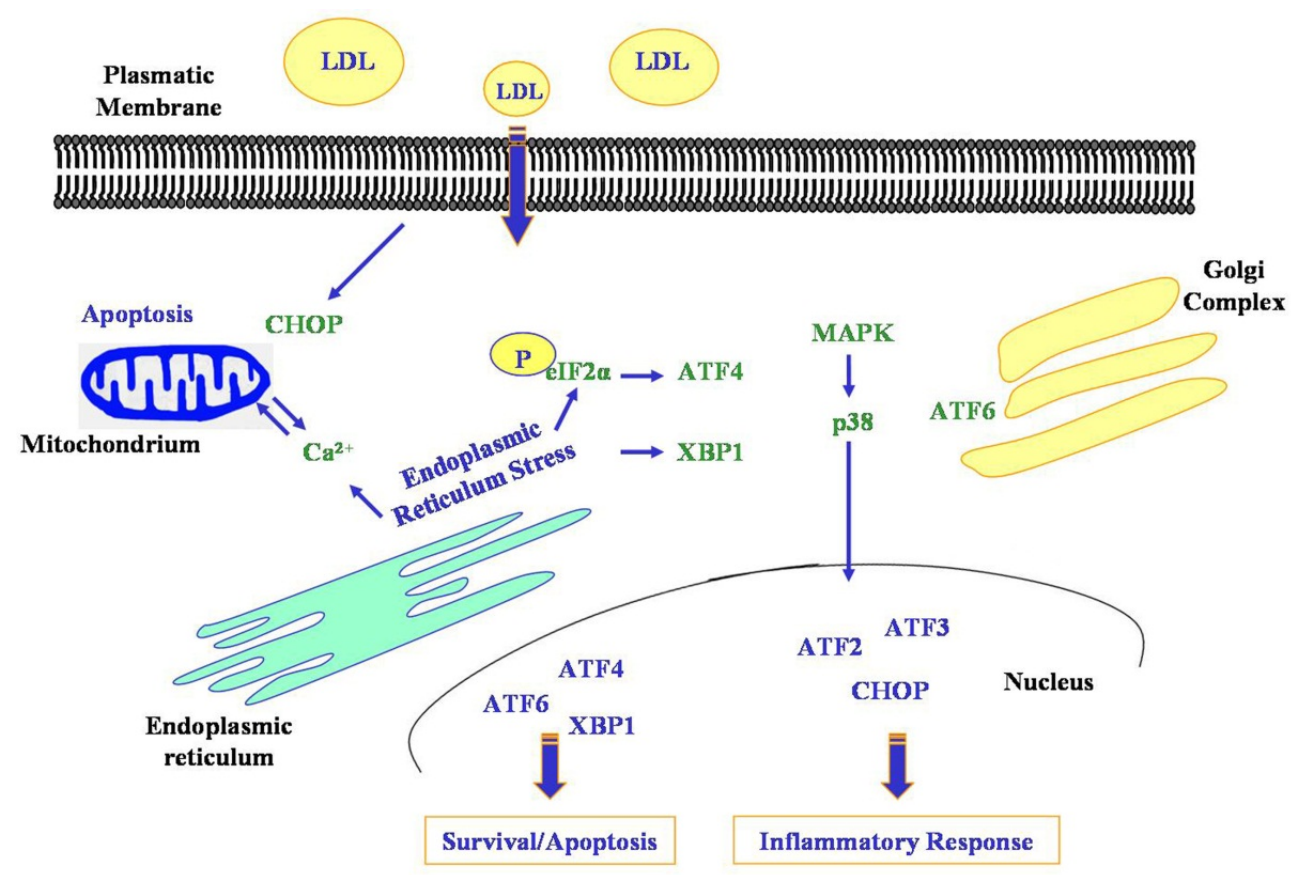

Figure 3. Multiple signaling triggered by lipoproteins in endothelial cells. ATF- activating transcription factors $2,3,4$, 6; LDL- low density lipoproteins; CHOP- C/EBP homologous protein; XBP1- x-box binding protein 1; elF2alpha- initiation factor 2 alpha; MAPK- mitogen activated protein kinase. Adapted by [117].

However not only in the initial pro-atherogenic phase but also in advanced phase, associated to the plaque rupture, it is crucial that the endothelium maintains its integrity, so hampering the diffusion in the blood of the circulating plaque. 
In particular during this advanced step, it has been reported that increased apoptotic endothelial cells may act as a pro-coagulant and favor the increase of platelet adhesion during the plaque erosion [118].

In human coronary arteries plaque vulnerability is associated to the expression of ER stress proteins like CHOP and macrophage apoptosis $[119,120]$.

Unlike clinical patients, murine animal model of atherosclerosis are unsuited for studying plaque disruption or acute thrombosis, so they are currently studied to characterize early atherosclerotic phases up to necrotic plaque [121].

Recently in CHOP-deficient mice mated with $\mathrm{ApoE}^{-/-}$atherosclerotic mice, it has been demonstrated a direct causal link between reduced CHOP-induced apoptosis and plaque necrosis [122]. In this double transgenic model, ER stress has different impacts on the vascular damage, according to the lesion stage of the artery. Indeed it is possible that in an early atherogenic phase, the UPR mechanism may be protective in macrophages and smooth muscle cells, but after persistent damage, the UPR-induced apoptosis is associated to plaque vulnerability and rupture.

Besides the endothelium, also smooth muscle cells in artery wall can be susceptible to ER stress-UPR and compromise plaque integrity by reducing the protective fibrous cap in advanced atherosclerosis [123].

Moreover atherogenic stressors like cholesterol and homocysteine are able to up-regulate $\mathrm{CHOP}$ and apoptosis in smooth muscle cells in vitro [124]. Indeed in human aortic cells the delivery of 7-ketocholesterol, an oxysterol linked in patients to high cardiovascular risk and atherosclerosis, activated UPR pathway up to apoptosis [125].

However unfortunately clear molecular evidences of pathways linking UPR to smooth muscle cells in atherosclerosis are still lacking. This is not true for macrophages, and the role of UPR in macrophages apoptosis is an emerging field of investigation [91].

Remarkably in atherosclerosis dual impact of macrophages resistance to apoptosis has been related to different stages of the disease: it may be beneficial in early lesions, where they hinder inflammation, but is detrimental in advanced phases, where they contribute to a significant increase in the lesion size associated to elevated chemokines expression and monocytes recruitment [126].

Furthermore it is important to point out that if inflammatory foam cells in the sub-endothelium space are cleared by active macrophages to prevent further secondary necrosis, in parallel many inflammatory pathways are activate to potentiate atherogenic damage, including nuclear factor k-B (NFkB) and mitogen-activated protein kinase (MAPK), in particular p38MAPK cascade [127].

As commonly accepted, the chronic activation of the three canonical UPR pathways in the ER, triggers different pro-apoptotic mechanisms in the vascular wall, that may be mitochondria-dependent or independent, but largely complementary and integrated [128]. 
The most common death-sensors activated in the mitochondria are: 1) the stimulation of inositol requiring protein-1 (IRE1) that can further regulate B-cell lymphoma-2 (BCL-2) family of proteins and 2) PERK and ATF6 signals that directly induce CHOP/GADD153 protein. Remarkably, CHOP is also involved in the activation of a mitochondria-independent mechanism of apoptosis that relies on inositol-1,4,5-triphosphate receptor (IP3R), able to trigger abnormal calcium $\left(\mathrm{Ca}^{2+}\right)$ flux from the ER and the death receptor Fas [129].

Although three branches may be activated by any prolonged stressful event, the timing of each pathway can differ and persistent ER stress leads to sequential progression of IRE1, then ATF6, finally PERK respectively. Moreover it is important to outline that each proapoptotic mechanism is strictly cell-type and stimulus-specific.

IRE 1 isoforms are activated by auto-phosphorylation and trigger the splicing and translation of mRNA transcript for a specific transcription factor, called XBP1s, that induces chaperones and other molecules able to limit ER stress.

However in mammalian cells, IRE1 stimulates also another mechanism known as regulated IRE1 dependent decay (RIDD) [130], that may directly lead to apoptosis even if this branch is still controversial in cardiovascular diseases.

Nevertheless the major downstream effector of IRE1 signaling is the BCL-2 family of proteins, that includes both anti-apoptotic and pro-apoptotic members able to regulate the activity of ER and mitochondria [131].

In human and mice anti-apoptotic domains are called Bcl-2 and Bcl-XL, while the most well characterized pro-apoptotic are Bcl2-associated $x$ protein (BAX) and Bcl2-homologous antagonist (BAK) proteins. When these last two members become activated in the mitochondria, release cytochrome $\mathrm{c}$ and other death factors that may amplify the caspases cascade up to overt cell death. Despite in vitro observations on IRE1 signaling, actually there is not yet in vivo evidence for apoptosis along this pathway [132].

Remarkably CHOP signaling is common also to PERK and ATF6 pathways in the ER stress response, where it may act like in the IRE1, even if there is the possibility to by-pass the mitochondria and to stimulate calcium flux, working on the ER calcium channel called inositol-1, 4, 5-triphosphate or IP3R [133].

Many recent studies point to the apoptotic mechanism driven by calcium release from the ER lumen, able to stimulate the calcium-sensing enzyme called calcium/calmodulin-dependent protein kinase, CaMK II, which in turn regulates other apoptotic pathways, like FAS activation but also caspase 12 [134,135].

In advanced atherosclerosis, the level of ER stress-CHOP expression in macrophages is very high despite the presence of TRLs ligands and the activation of TRIF-signaling. A crucial concept in the regulation of macrophage apoptosis in atherosclerosis is called "the two-hit concept", that consists in the eventuality of a milder ER stress in vivo respect to in vitro. So different cumulative sub-apoptotic stimuli may lead to a synergic more effective response in the artery vessel, and in particular because generally TLRs act as a second pro-apoptotic stimuli. If this eventuality is lost as evident in advanced ruptured plaque and related throm- 
bosis, it may be due to an inability to resist to PERK and eIF2alpha signaling and to reduce downstream ATF4-CHOP associated apoptosis in vivo as recently hypothesized [136].

In Figure 4 we resumed complex relationships between ER signaling and apoptosis in atherogenesis.

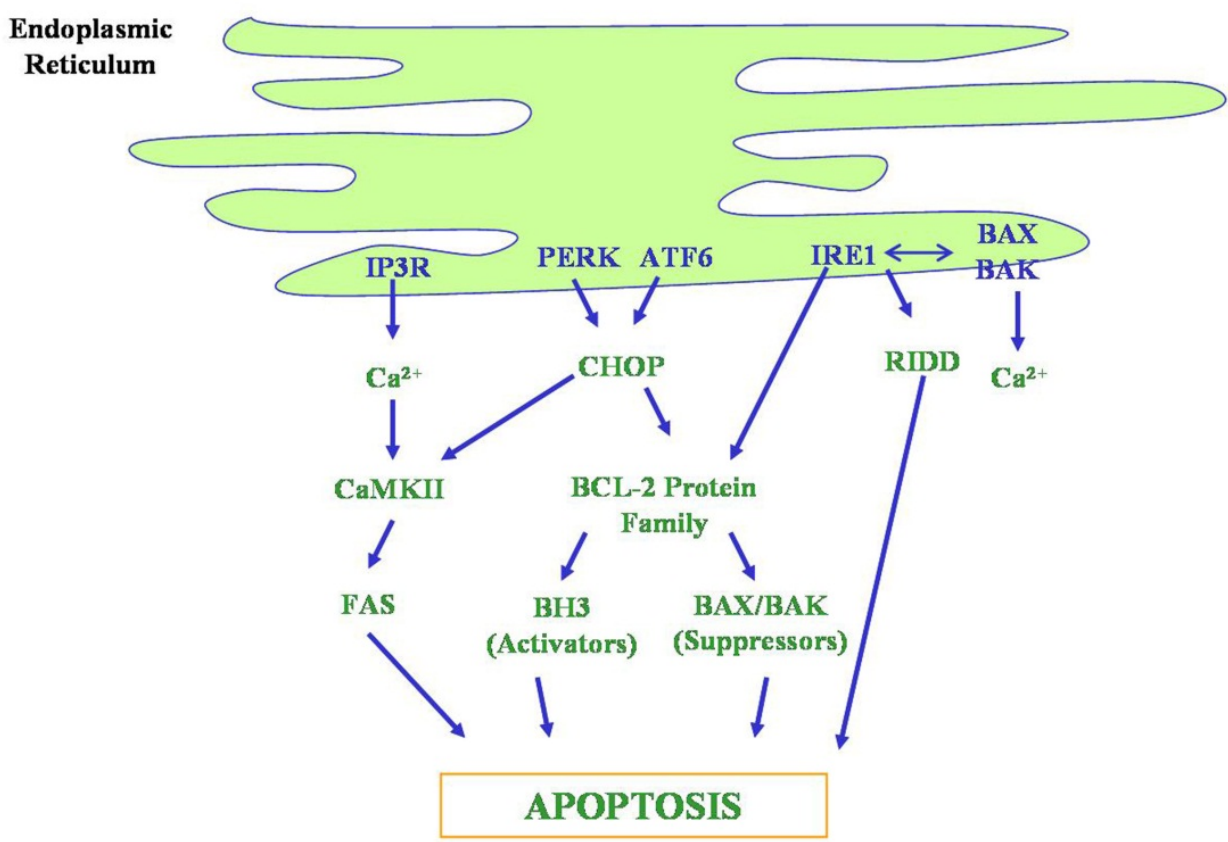

Figure 4. Different ER signals leading to successful apoptosis. IP3R- inositol -1,4, 5,-triphosphate receptor; PERK- protein kinase-like ER kinase; ATF6- activating transcription factor 6; IRE1-inositol requiring protein 1; BCL2- B cell lymphoma/leukemia 2; Bak- Bcl2-homologous antagonist; Bax- Bcl2-associated x protein; RIDD- regulated IRE1-dependent decay; CaMK II- calcium/calmodulin-dependent protein kinase; FAS- tumor necrosis factor receptor superfamily member 6; CHOP- C/EBP homologous protein; BH3- homology domain. Adapted by [107].

\section{ER stress as a therapeutic target in atherosclerosis and metabolic diseases}

In metabolic diseases such as atherosclerosis, hypertension, diabetes and related cardiovascular complications, improved understanding of ER stress pathways and their relationship with inflammation and apoptosis represents the basis on which to try novel drugs, to test therapeutic interventions and to identify targets for different therapeutic options. 
In cardiovascular diseases but also in the endothelial cells and cardiomyocytes in vitro, the regulation of the UPR arms can lead to an adaptation phase and survival or to a detrimental phase that ends into cell death.

These opposite effects, considered as "the double-edged sword", are an important issue for vascular biology, even if the molecular mechanisms that differentially regulate survival or cell death are yet to be clarified $[137,138]$.

Anyway, it is possible to resume ER-regulatory interventions into two types: 1) one directly targeting ER stress-UPR by interfering with UPR branches with the use of chemical chaperones or inhibitors; 2) others indirectly targeting ER stress-UPR by regulation of related apoptosis, autophagy, oxidative or inflammatory signaling.

It is established that diabetic retinopathy is a major complication of diabetes, associated to inflammation and leukocyte adhesion in the endothelium of retinal vasculature, that impairs the inner blood-retinal barrier necessary to normal visual activity [139].

Recently ER stress has been involved in the pathogenesis of this invalidating disease [140]. However when used as a preconditioning tool, it may provide therapeutic benefits.

In particular the activation of XBP1s in endothelial cells, negatively regulates IRE1-alpha phosphorylation and suppresses inflammation. So, improving this branch of ER stress pathway may be useful to prevent or limit retinopathy in diabetes [141].

Furthermore emerging data on angiotensin II-induced cardiac hypertrophy in mice, have demonstrated a direct involvement of ER stress and related markers, GRP78 and CHOP, in cardiac remodeling and fibrosis [18].

ER chaperones represent a group of low-molecular compounds able to increase ER folding capacity and alleviate the accumulation of dysfunctional proteins, so maintaining ER homeostasis [142]. Different chaperones like 4-phenyl butyrate (PBA) and taurine-conjugated deoxycholic acid (TUDCA) have been successfully tested in vivo in different murine models of atherosclerosis, diabetes and leptin resistance where ER stress was attenuated [143].

Moreover PBA and TUDCA, have been successfully tested against endothelium-dependent relaxation and oxidative damage in the aorta and mesenteric artery in hypertensive mice [19]. Indeed ER signaling might represent a potential target to reverse hypertension-induced vascular and cardiac dysfunctions.

In particular ER stress was linked also to oxidative damage, due to abnormal calcium flux from the ER driven by protein misfolding and its uptake into the mitochondria where calcium disrupted the electron transport chain [144]. Nevertheless further studies are required to elucidate how these two mechanisms can activate each other [145].

In a mouse model of type 2 diabetes chemical chaperones increased insulin sensitivity acting by antioxidant properties, this finding is particularly interesting because ER stress may also induce insulin-resistance [146,147].

A recent study performed in transgenic $\mathrm{ApoE}^{-/-}$mice, fed a Western diet, has supported the protective role of hydrogen sulfide, a product generated from L-cysteine catalyzed by cysta- 
thionine-L-lyase in the cardiovascular system, as an effective anti-atherosclerotic compound. Indeed it reduces oxidative damage in the aorta but also potentiates the adaptive beneficial role of ER signaling by increasing GRP78 expression in the intima layer. This effect might be related to the reduction of plasma level of LDL and lipids deposition in the aorta [148].

Furthermore up-regulation of T-cadherin has emerged as an effective tool that limits the progression of atherosclerotic lesions in endothelial cells in vitro. This molecule is a glycosylphosphatidylinositol-anchored element belonging to the cadherin family, that colocalizes with GRP78 on the plasma membrane [149]. Its over-expression or silencing by genetic manipulations selectively attenuates or amplifies the PERK branch of the UPR cascade obtained by ER stressors like homocysteine, thapsigargin and brefeldin A, so influencing apoptosis [150]. Indeed T-cadherin up-regulation is able to directly limit the phosphorylation of the eukaryotic translation initiation factor 2 alpha (phospho-eIF2alpha) and CHOP-driven cell death, even if how it communicates with ER-stress machinery in vitro is not yet known.

Salubrinal is another chemical chaperone that modulates the dephosphorylation of eIF2alpha, so reducing abnormal protein load on the ER and prolonged UPR, and it has been demonstrated to limit ischemia-reperfusion damage in the mice brain [151]. Despite some promising reports, it is important to consider that there are different commercial preparations of the drug providing different level of protection, so the real efficacy is currently debated.

Finally among ER-resident chemical chaperones oxygen-regulated protein150 (ORP150), a $150 \mathrm{kDa}$ oxygen-regulated protein, has been implicated not only in reducing apoptosis during oxidative damage but also in preventing ox-LDLs induced ER stress in transfected vascular endothelial cells. In particular, by immune-precipitation assay it has been demonstrated that ORP150 is bound to three ER stress sensors IRE1alpha, PERK and ATF6 so maintaining them in an inactive status and contributing to delay UPR activation. Furthermore ORP150 and IRE1alpha were also linked in situ in atherosclerotic lesions from human carotid plaque, but no ORP150-IRE1 alpha association was detected in normal human mammary artery [152].

A growing body of evidence indicates that LDLs, modified by oxidation, enzymatic attack, glycation and aggregation in ox-LDL, trigger local vascular inflammation and toxic events implicated in atherosclerosis, but in contrast high density lipoproteins (HDLs) have antiatherogenic properties that have been linked to reduced ER stress and autophagy [153].

In endothelial cells in vitro HDLs pretreatment was able to prevent detrimental UPR pathways inhibiting IRE1 alpha activation and phosphorylation in the PERK arm and the nuclear translocation of ATF6 that triggered the pro-apoptotic CHOP signaling. All these mechanisms were stimulated by prolonged ER stress induced by ox-LDLs that in parallel activated also autophagy then overwhelmed by apoptosis if the vascular stress lasted too much. However, calcium deregulation was a common upstream signal for two parallel pathways in this in vitro model, where ER stress-UPR but also autophagy are involved. Indeed HDLs were able to prevent the increase in autophagic markers like LC3-II and beclin-1 in the endothelial cells that, silenced for beclin 1 and then stimulated by toxic ox-LDLs, displayed less ability to be recognized by macrophages. 
Remarkably, even if autophagy is not involved in apoptosis, probably contributes like a beneficial "eat-me" signal on the cell surface by exposing phosphatydylserine, necessary to the clearance by efferocytosis of apoptotic cells [154] (Figure 5). All these important findings suggest a potential efficacy for HDLs-based therapeutic opportunities in atherosclerosis.

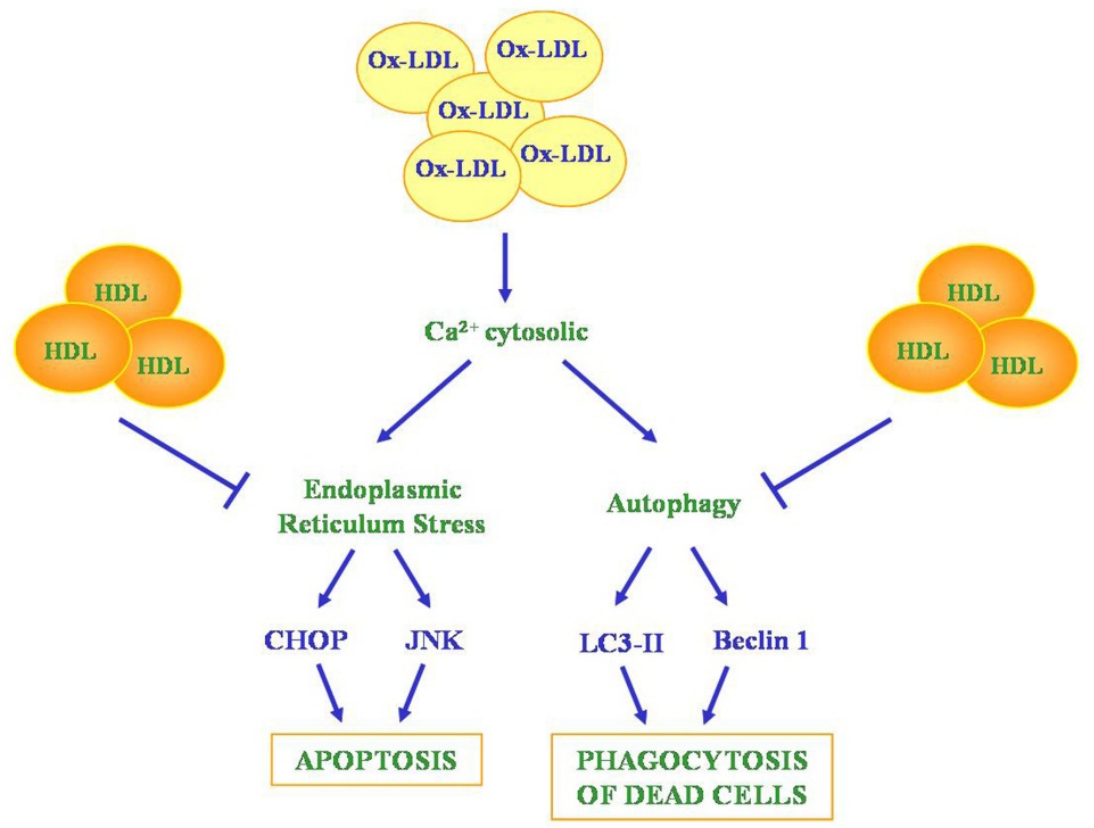

Figure 5. Beneficial role of high density lipoproteins upstream ER stress and autophagy in endothelial cells. HDL- high density lipoprotein; LDL: low density lipoprotein; ox-LDL- oxidized lipoproteins; LC3-II- microtubule-associated protein1 light chain 3; CHOP- C/EBP homologous protein; JNK- c-Jun N-terminal kinase. Adapted from [154].

Recently an interesting study reported the peculiar expression on endothelial cells and macrophages of a novel GRP78-interacting protein induced by ER stress, called Gipie [155]. Gipie belongs to the Girdin family protein and is localized in the ER and Golgi apparatus in the endothelial cell lines (human umbilical vein endothelial cell-HUVEC and human coronary artery endothelial cells-HCAEC), but not in epithelial or mesenchymal cells in vitro. The transfection of Gipie into HUVEC cells exposed to ER inducer thapsigargin, a specific blocker of ER calcium ATP-ase pumps, was able to decrease $\mathrm{CHOP}$ expression and apoptosis.

Moreover the same protection was demonstrated by Gipie's over-expression in rat carotid artery endothelial cells after baloon injury, a well-known in vivo model of endothelial damage and restenosis. Finally also in adult P65 mice aorta, Gipie was superimposed with GRP78 in atheroprone sites like the inner curvature of the aortic arch, but not in the outer curvature or in the ascending aorta, less sensitive to hemodynamic stress. By interaction with GRP78, Gipie modulates IRE1/JNK signaling and CHOP expression, so reducing apop- 
tosis, even if the detailed mechanism by which it regulates GRP78/IRE1 activation is still unknown. Anyway even if more studies on transgenic Gipie-deficient animals will improve the understanding of the proper function in circulatory system, Gipie may be considered a reliable therapeutic target in atherosclerosis yet.

\section{Conclusions}

Actually the pivotal role of ER stress response in atherosclerosis and cardiovascular diseases is widely accepted. Nevertheless it remains much work to do in particular to discover the multiple relationship between different integrated pathways associated to ER signaling and to maintain the best ER stress modulation in the endothelium and vascular wall. Indeed it is important to point out that in biology the UPR is considered a surviving mechanism, so its complete deregulation may not be useful but dangerous. However additional experimental studies are required to help identify novel therapies to restore proper ER homeostasis but in particular, those to stabilize the minority of dangerous plaques associated with acute cardiovascular damage.

\section{Acknowledgements}

This chapter is supported by academic grants (ex MIUR 60\% 2011-2012).

\section{Author details}

Alessandra Stacchiotti, Gaia Favero and Rita Rezzani

*Address all correspondence to: stacchio@med.unibs.it

Human Anatomy Division, Department of Biomedical Sciences and Biotechnology, University of Brescia, Brescia, Italy

\section{References}

[1] Hansson G, Robertson A, Soderberg-Naucler C. Inflammation and atherosclerosis. Ann Rev Pathol 2006;1 297-329.

[2] Packard R, Libby P. Inflammation in atherosclerosis: from vascular biology to biomarker discovery and risk prediction. Clin Chem 2008;54(1) 24-38.

[3] Mulligan-Kehoe M. The vasa vasorum in diseased and non diseased arteries. Am J Physiol Heart Circ Physiol 2010;298 H-295-H305 
[4] Torsny E, Xu Q. Resident vascular progenitor cells. J Mol Cell Cardiol 2011;50 304-311

[5] Vasuri F, Fittipaldi S, Buzzi M, Degiovanni A, Stella A, D’Errico-Grigioni A, Pasquinelli G. Nestin and WT1 in normal vasa vasorum. Histol Histopathol 2012;27(9) 1195-1202.

[6] Dai G, Vaughn S, Zhang Y, Wang E, Garcia-Cardena G, Gimbrone M. Biomechanical forces in atherosclerosis resistant vascular regions regulate endothelial redox balance via phosphoinositol-3-kinase/Akt-dependent activation of Nrf2. Circ Res 2007;101 723-733.

[7] van Hinsbergh V, van Niew Amerongen G. Intracellular signaling involved in modulating human endothelial barrier function. J Anat 2002;200(6) 549-560.

[8] Ozcan U, Cao Q, Yilmaz E, Lee A, Iwakoshi N, Ozdelen E, Tuncman G, Gorgun C, Glimcher L, Hotamisligil G. Endoplasmic reticulum stress links obesity, insulin action, and type 2 diabetes. Science 2004;306(5695) 457-461.

[9] Marciniak S, Ron D. Endoplasmic reticulum stress signaling in disease. Physiol Rev 2006;86(4) 1133-1149.

[10] Yoshida H. ER stress and diseases. FEBS Journal 2007;274(3) 630-658.

[11] Groenendyk J, Sreenivasaiah K, Kim D, Agellon L, Michalak M. Biology of endoplasmic reticulum stress in the heart. Circ Res 2010;107 1185-1197.

[12] Tabas I. The role of endoplasmic reticulum stress in the progression of atherosclerosis. Circ Res 2010;107(7) 839-850.

[13] Witte I, Horke S. Assessment of endoplasmic reticulum stress and the unfolded protein response in endothelial cells. In: M.Conn (ed.) Methods in Enzymology. Burlington: Academic Press; 2011. Vol.489, p.127-146.

[14] Mc Gill H, Mc Mahan C. Determinants of atherosclerosis in the young. Pathobiological determinants of atherosclerosis in youth (PDAY) research group. Am J Cardiol 1998;82 30T-36T.

[15] Minamino T, Kitakaze M. ER stress in cardiovascular disease. J Mol Cell Cardiol 2010;48(6) 1105-1110.

[16] Xu J, Wang G, Wang Y, Liu Q, Xu W, Tan Y, Cai L. Diabetes and angiotensin II-induced cardiac endoplasmic reticulum stress and cell death: metallothionein protection. J Cell Mol Med 2009;13(8A) 1499-1512.

[17] Tycinska A, Mroczko B, Musial W, Sawicki R, Kaminski K, Borowska H, Sobkowicz $\mathrm{B}$, Smitkowski M. Blood pressure in relation to neurogenic, inflammatory and endothelial dysfunction biomarkers in patients with treated essential arterial hypertension. Adv Med Sci 2011;56 80-87. 
[18] Minamino T, Komuro I, Kitakaze M. Endoplasmic reticulum stress as a therapeutic target in cardiovascular disease. Circ Res 2010;107(9) 1071-1082.

[19] Kassan M, Galan M, Partyka M, Saifudeen Z, Henrion D, Trebak M, Matrougui K Endoplasmic reticulum stress is involved in cardiac damage and vascular endothelial dysfunction in hypertensive mice. Arterioscler Thromb Vasc Biol 2012;32(7) 1652-1661.

[20] Hansson G. Inflammation, atherosclerosis, and coronary artery disease. N Engl J Med 2005;352 1685-1695.

[21] Sima AV, Stancu C, Simionescu M. Vascular endothelium in atherosclerosis. Cell Tissue Res 2009;335 191-193.

[22] Libby P, Ridker P, Hansson G. Inflammation in atherosclerosis: from pathophysiology to practice. J Am Coll Cardiol 2009;54 2129-2138.

[23] Zhang K. Integration of ER stress, oxidative stress and the inflammatory response in health and disease. Int J Clin Exp Med 2010;3 33-40.

[24] Curtiss L, Tobias P. Emerging role of Toll-like receptors in atherosclerosis. J Lipid Res 2009; 50 S340-S345.

[25] Davies P. Hemodynamic shear stress and the endothelium in cardiovascular pathophysiology. Nat Clin Pract Cardiovasc Med 2009;6 16-26.

[26] Chen Y, Jan K, Chien S. Ultrastructural studies on macromolecular permeability in relation to endothelial cell turnover. Atherosclerosis 1995;118(1) 89-104.

[27] Martinez-Lemus L, Hill M, Meininger G. The plastic nature of the vascular wall: a continuum of remodeling events contributing to control of arteriolar diameter and structure. Physiology 2009;24(1) 45-57.

[28] Bonetti P, Lerman L, Lerman A. Endothelial dysfunction a marker of atherosclerotic risk. Atheroscler Thromb Vasc Biol 2003;23(2) 168-175.

[29] Davies P, Civelek M, Fang Y, Guerraty M, Passerini A. Endothelial heterogeneity associated with regional athero-susceptibility and adaptation to disturbed blood flow in vivo. Semin Thromb Hemost 2010;36(3) 265-275.

[30] Xu Q. Biomechanical stress induced signaling and gene expression in the development of arteriosclerosis. Trends Cardiovasc Med 2000;10 35-41

[31] Xu Q. Disturbed flow-enhanced endothelial turnover in atherosclerosis. Trends Cardiovasc Med 2009;19 191-195.

[32] Simmons C, Grant G, Manduchi E, Davies P. Spatial heterogeneity of endothelial phenotypes correlates with side-specific vulnerability to calcification in normal porcine aortic valves. Circ Res 2005;96(7) 792-799. 
[33] Rodella LF, Rezzani R. Endothelial and vascular smooth cell dysfunctions: a comprehensive appraisal. In: Parthasaraty S. (ed.) Atherogenesis. Rijeka: InTech; 2011. p. 105-134.

[34] Luscher T, Barton M. Biology of the endothelium. Clin Cardiol 1997;20 (11) 3-10.

[35] Masuda H, Kawamura K, Nanjo H, Sho E, Komatsu M, Sugiyama T, Sugita A, Asari Y, Kobayashi M, Ebina T, Hoshi N, Singh TM, Xu C, Zarins CK. Ultrastructure of endothelial cells under flow alteration. Microsc Res Tech 2003;60(1) 2-12.

[36] Nico B, Crivellato E, Ribatti D. The importance of electron microscopy in the study of capillary endothelial cells: an historical review. Endothelium 2007;14(6) 257-264.

[37] Berriman J, Li S, Hewlett L, Wasilewski S, Kiskin F, Carter T, Hannah M, Rosenthal P. Structural organization of Weibel-Palade bodies revealed by cryo-EM of vitrified endothelial cells. Proc Natl Acad Sci USA 2009;106(41) 17407-17412.

[38] Valentijn K, Valentijn J, Jansen K, Koster A. A new look at Weibel-palade body structure in endothelial cells using electron tomography. J Struct Biol 2008;161(3) 447-458.

[39] Rondaij M, Bierings R, Kragt A, van Mourik J, Voorberg J. Dynamics and plasticity of Weibel-Palade bodies in endothelial cells. Arterioscler Thromb Vasc Biol 2006;26 1002-1007.

[40] Simionescu M, Gafencu A, Antohe F. Transcytosis of plasma macromolecules in endothelial cells: a biological survey. Microsc Res Tech 2002;57 269-288.

[41] van den Berg B, Spaan J, Vink H. Impaired glycocalyx barrier properties contribute to enhanced intimal low-density lipoprotein accumulation at the carotid artery bifurcation in mice. Pflugers Arch 2009;457 1199-1206.

[42] Simionescu M. Implications of early structural-functional changes in the endothelium for vascular disease. Arterioscler Thromb Vasc Biol 2007;27 266-274.

[43] Zhang K, Kaufman R. From endoplasmic-reticulum stress to the inflammatory response. Nature 2008;454(7203) 455-462.

[44] Civelek M, Manduchi E, Riley R, Stoekert C, Davies P. Coronary artery endothelial transcriptome in vivo. Identification of endoplasmic reticulum stress and enhanced reactive oxygen species by gene connectivity network analysis. Circ Cardiovasc Genet 2011;4 243-252.

[45] Burridge K, Friedman M. Environment and vascular bed origin influence differences in endothelial transcriptional profiles of coronary and iliac arteries. Am J Physiol Heart Circ Physiol 2010;299(3) H837-H846.

[46] Dancu M, Tarbell J. Coronary endothelium expresses a pathologic gene pattern compared to aortic endothelium: correlation of asynchronous hemodynamics and pathology in vivo. Atherosclerosis 2007;192 9-14. 
[47] Voeltz G, Rolls M, Rapoport T. Structural organization of the endoplasmic reticulum. EMBO Rep 2002;3(10) 944-950.

[48] Friedman J, Voeltz G. The ER in 3D: a multifunctional dynamic membrane network. Trends Cell Biol 2011;21(12) 709-717.

[49] Csordas G, Renken C, Varnai P, Walter L, Weaver D, Buttle K, Balla T, Mannella C, Hainoczky G. Structural and functional features and significance of the physical linkage between ER and the mitochondria. J Cell Biol 2006;174(7) 915-921.

[50] Shibata Y, Voeltz G, Rapoport T. Rough sheets and smooth tubules. Cell 2006;126(3) 435-439.

[51] Michalack M, Opas M. Endoplasmic and sarcoplasmic reticulum in the heart. Trends Cell Biol 2009;19 253-259.

[52] Lavoie C, Roy L, Lanoix J, Taheri M, Young R, Thibault G, Farah C, Leclerc N, Paiement J. Taking organelles apart, putting them back together and creating new ones: lessons from the endoplasmic reticulum. Prog Histochem Cytochem 2011;46(1) 1-48.

[53] Eligaard L, Helenius A. Quality control in the endoplasmic reticulum. Nat Rev Mol Cell 2003;4 181-191.

[54] Schroeder M. Endoplasmic reticulum stress responses. Cell Mol Life Sci.2008;65 862-894.

[55] Rutkowski D, Kaufman R. That which does not kill me makes me stronger: adapting to chronic ER stress. Trends Biochem Sci 2007;32(10) 469-475.

[56] Kopito R. ER quality control: the cytoplasmic connection. Cell 1997;88 427-430.

[57] Meusser B, Hirsch C, Jarosch E, Sommer T. ERAD: the long road to destruction. Nat Cell Biol 2005;7 766-772.

[58] Travers K, Patil C, Wodicka L, Lockhart D, Weissman J, Walter P. Functional and genomic analyses reveal an essential coordination between the unfolded protein response and ER-associated degradation. Cell 2000;101 249-258.

[59] Mori K. Tripartite management of unfolded proteins in the endoplasmic reticulum. Cell 2000;101 451-454.

[60] Schroder M, Kaufman R. ER stress and the unfolded protein response. Mutat Res 2005;569 29-63.

[61] Credle J, Finer-Moore J, Papa F, Stroud R, Walter P. On the mechanism of sensing unfolded protein in the endoplasmic reticulum. Proc Natl Acad Sci USA 2005;102 18773-18784.

[62] Hollien J, Weissman J. Decay of endoplasmic reticulum-localized mRNAs during the unfolded protein response. Science 2006;313 104-107. 
[63] Oyadomari S, Mori M. Roles of CHOP/GADD 153 in endoplasmic reticulum stress. Cell Death Differ 2004;11(4) 381-389.

[64] Woehlbier U, Hetz C. Modulating stress responses by the UPRosome: A matter of life and death. Trends in Biochem Sciences 2011;36(6) 329-337.

[65] Broadley S, Hartl F. The role of molecular chaperones in human misfolding diseases. FEBS Letters 2009;583 2647-2653.

[66] Ma Y, Hendershot L. ER chaperone functions during normal and stress conditions. J Chem Neuroanat 2004;28 51-65.

[67] Radford S. Protein folding: progress made and promises ahead. Trends Biochem Sci 2000;25 611-618.

[68] Hayes D, Napoli V, Mazurkie A, Stafford W, Graceffa P. Phosphorylation dependence of Hsp27 multimeric size and molecular chaperone function. J Biol Chem $2009 ; 284$ 18801-18807.

[69] Hartl F, Bracher A, Hayer-Hartl M. Molecular chaperones in protein folding and proteostasis. Nature 2011;475 324-332.

[70] Ron D, Walter P. Signal integration in the endoplasmic reticulum unfolded protein response. Nat Rev Mol Cell Biol 2007;8(7) 519-529.

[71] Little E, Ramakrishman M, Roy B, Gazit G, Lee A. The glucose-regulated proteins (GRP78 and GRP94): Functions, gene regulation, and applications. Crit Rev Euk Gene Exp 1994;4 1-18.

[72] Bertolotti A, Zhang Y, Hendershot L, Harding H, Ron D. Dynamic interaction of BiP and ER stress transducers in the unfolded-protein response. Nat Cell Biol 2000;2(6) 326-332.

[73] Feng B, Yao P, Li Y, Devlin C, Zhang D, Harding H, Sweeney M, Rong J, Kuriakose G, Fisher E, Marks A, Ron D, Tabas I. The endoplasmic reticulum is the site of cholesterol-induced cytotoxicity in macrophages. Nat Cell Biol 2003;5 781-792.

[74] Outinen P, Sood S, Pfeifer S, Pamidi S, Podor T, Weitz J, Austin R. Homocysteineinduced endoplasmic reticulum stress and growth arrest leads to specific changes in gene expression in human vascular endothelial cells. Blood 1999;94 959-967.

[75] Feaver R, Hastings N, Pryor A, Blackman B. GRP78 upregulation by atheroprone shear stress via p38-, alpha2beta1-dependent mechanism in endothelial cells. Arterioscler Thromb Vasc Biol 2008;28(8) 1534-1541.

[76] Orr A, Sanders J, Bevard M, Coleman E, Sarembock I, Schwartz M. The subendothelial extracellular matrix modulates NFkB activation by flow: a potential role in atherosclerosis. J Cell Biol 2005;169 191-202. 
[77] Luo S, Mao C, Lee B, Lee A. GRP78/BiP is required for cell proliferation and protecting the inner cell mass from apoptosis during early mouse embryonic development. Mol Cell Biol 2006;26 5688-5697.

[78] Dickhout J, Carlisle R, Austin R. Interrelationship between cardiac hypertrophy, heart failure, and chronic kidney disease. Endoplasmic stress as a mediator of pathogenesis. Circ Res 2011;108(5) 629-642.

[79] Acosta-Alvear D, Zhou Y, Blais A, Tsikitis M, Lents N, Arias C, Lennon C, Kluger Y et al. XBP1 control diverse cell type- and condition-specific transcriptional regulatory networks. Mol Cell 2007;27 53-66.

[80] Belmont P, Chen W, San Pedro M et al. Roles for endoplasmic reticulum-associated degradation and the novel endoplasmic reticulum stress response gene derlin-3 in the ischemic heart. Circ Res 2010;106(2) 307-316.

[81] Herrmann J, Soares S, Lerman L, Lerman A. Potential role of the ubiquitin-proteasome system in atherosclerosis. J Am Coll Cardiol 2008;51(21) 2003-2010.

[82] Bernales S, McDonald K, Walter P. Autophagy counterbalances endoplasmic reticulum expansion during the unfolded protein response. PLoS Biol 2006;4 e423.

[83] Yorimitsu T, Klionsky D. Endoplasmic reticulum stress: a new pathway to induce autophagy. Autophagy 2007;3(2)160-162.

[84] Wu F, Terada L. Focal oxidant and Ras signaling on the ER surface activates autophagy. Autophagy 2010;6(6) 828-829.

[85] Ogata M, Hino S, Saito A, Morikawa K, Kondo S, Kanemoto S, et al. Autophagy is activated for cell survival after endoplasmic reticulum stress. Mol Cell Biol 2006;26(24) 9220-9231.

[86] Gustafsson A, Gottlieb R. Autophagy in ischemic heart disease. Circ Res 2009;104(2) 150-158.

[87] Schrijvers D, De Meyer G, Martinet W. Autophagy in atherosclerosis. A potential drug target for plaque stabilization. Arterioscl Thromb Vasc Biol 2011;31(12) 2787-2791.

[88] Gottlieb R, Finley K, Mentzer R. Cardioprotection requires taking out the trash. Bas Res Cardiol 2009;104 169-180.

[89] Nemchenko A, Chiong M, Turer A, Lavandero S, Hill J. Autophagy as a therapeutic target in cardiovascular disease. J Mol Cell Cardiol 2011;51(4) 584-593.

[90] Gottlieb R, Mentzer R. Cardioprotection through autophagy: ready for clinical trial? Autophagy 2011;7 434-435.

[91] Moore K, Tabas I. Macrophages in the pathogenesis of atherosclerosis. Cell 2011;145 341-355. 
[92] Thorp E, Tabas I. Mechanisms and consequences of efferocytosis in advanced atherosclerosis. J Leukoc Biol 2009;86 1089-1095.

[93] Croons V, Martinet W, De Meyer G. Selective removal of macrophages in atherosclerotic plaques as a pharmacological approach for plaque stabilization: benefits versus potential complications. Curr Vasc Pharmacol 2010;8(4) 495-508.

[94] Van Vre E, Ait-Outfella H, Tedgui A, Mallat Z. Apoptotic cell death and efferocytosis in atherosclerosis. Arterioscl Thromb Vasc Biol 2012;32 887-893.

[95] Mahley R, Weisgraber K, Huang Y. Apolipoprotein E: structure determines function, from atherosclerosis to Alzheimer's disease to AIDS. J Lipid Res 2009;50 S183-S188.

[96] Cash J, Kuhel D, Basford J, Jaeschke A, Chatterjee T, Weintraub N, Hui D. Apolipoprotein E4 impairs macrophage efferocytosis and potentiates apoptosis by accelerating endoplasmic reticulum stress. J Biol Chem 2012;287(33) 27876-27884.

[97] Ni M, Lee A. ER chaperones in mammalian development and human diseases. FEBS Letters 2007;581 3641-3651.

[98] Kaufman R. Orchestrating the unfolded protein response in health and disease. J Clin Invest 2002;110 1389-1398.

[99] Sitia R, Braakman I. Quality control in the endoplasmic reticulum protein factory. Nature 2003;426(6968) 891-894.

[100] Hebert D, Molinari M. In and out of the ER: Protein folding, quality control, degradation, and related human diseases. Physiol Rev 2007;87 1377-1408.

[101] Ozcan L, Tabas I. Role of endoplasmic reticulum stress in metabolic disease and other disorders. Ann Rev Med 2012;63 317-328.

[102] Ursini T, Davies K, Maiorino M, Parasassi T, Sevanian A. Atherosclerosis: another protein misfolding disease? Trends Mol Med 2002;8(8) 370-374.

[103] Hotamisligil G. Endoplasmic reticulum stress and atherosclerosis. Nature Med 2010;16(4) 396-399.

[104] Granados D, Tanguay P, Hardy M, Caron E, de Verteuil D, Meloche S, Perreault C. ER stress affects processing of MHC class I-associated peptides. BMC Immunol 2009;10 10.

[105] Dickout J, Colgan S, Lhotak S, Austin R. Increased endoplasmic reticulum stress in atherosclerotic plaques associated with acute coronary syndrome- a balancing act between plaque stability and rupture. Circulation 2007;116 1214-1216.

[106] Azfer A, Niu J, Rogers L, Adamski F, Kolattukudy P. Activation of endoplasmic reticulum stress response during the development of ischemic heart disease. Am J Physiol Heart Circ Physiol 2006;291 H1411-H1420.

[107] Scull, C, Tabas I. Mechanisms of ER stress-induced apoptosis in the atherosclerosis. Arterioscler Thromb Vasc Biol 2011;31(12) 2792-2797. 
[108] Zinszner H, Kuroda M, Wang X, Batchvarova N, Lightfoot R, Remotti H et al. CHOP is implicated in programmed cell death in response to impaired function of the endoplasmic reticulum. Genes Dev 1998;12 982-995.

[109] Myoshi M, Hao H, Minamino T, Watanabe K, Nishihira K, Hatakeyama K, Asada Y, Okada K, Ishibashi-Ueda $\mathrm{H}$ et al. Increased endoplasmic reticulum stress in atherosclerotic plaques associated with acute coronary syndrome. 2007;116 1226-1233.

[110] Nakashima Y, Plump A, Raines E, Breslow J, Ross R. Apo-E deficient mice develop lesions of all phases of atherosclerosis throughout the arterial tree. Arterioscler Thromb 1994;14 133-140.

[111] Zhou J, Lhotak S, Hilditch B, Austin R. Activation of the unfolded protein response occurs at all stages of atherosclerotic lesion development in apolipoprotein E-deficient mice. Circulation 2005;111 1814-1821.

[112] Zhou J, Werstuck G, Lhotak S, de Koning A, Sood S, Hossain G, Moller J, RitskesHointinga M, Falk E, Dayal S, Lentz S, Austin R. Association of multiple cellular stress pathways with accelerated atherosclerosis in hyperhomocysteinemic apolipoprotein E-deficient mice. Circulation 2004;110 207-213.

[113] Tsukano H, Gotoh T, Endo M, Miyata K, Tazume H, Kadomatsu T, Yano M, Iwawaki T, Kohno K, Araki K, Mizuta H, Oike Y. The endoplasmic reticulum stress-C/EBP homologous protein pathway-mediated apoptosis in macrophages contributes to the instability of atherosclerotic plaques. Arterioscler Thromb Vasc Biol 2010;30(10) 1925-1932.

[114] Zhang C, Cai Y, Adachi M, Oshiro S, Aso T, Kaufman R, Kitajima S. Homocysteine induces programmed cell death in human vascular endothelial cells through activation of the unfolded protein response. J Biol Chem 2001;276 35867-35874.

[115] Dickout J, Hossain G, Pozza L, Zhou J, Lhotak S, Austin R. Peroxynitrite causes endoplasmic reticulum stress and apoptosis in human vascular endothelium: implications in atherogenesis. Arterioscler Thromb Vasc Biol 2005;25 2623-2629.

[116] Zheng L, Zampetaki A, Margariti A, Pepe A, Alam S, Martin D et al. Sustained activation of XBP1 splicing leads to endothelial apoptosis and atherosclerosis development in response to disturbed flow. Proc Natl Acad Sci USA 2009; 106(20): 8326-8331

[117] Gora S, Maouche S, Atout R, Wanherdrick K, Lambeau G, Cambien F, Ninio E, Karabina S. Phospholipolyzed LDL in17duces an inflammatory response in endothelial cells through endoplasmic reticulum stress signaling. FASEB J 2010;24(9) 3284-3297.

[118] Bombeli T, Karsan A, Tait J, Harlan J. Apoptotic vascular endothelial cells become pro-coagulant. Blood 1997;89 2429-2442.

[119] Seimon T, Tabas I. Mechanisms and consequences of macrophage apoptosis in atherosclerosis. J Lipid Res 2009,50Suppl S382-S387. 
[120] Tabas I. Macrophage death and defective inflammation resolution in atherosclerosis. Nat Rev Immunol 2010;10(1) 36-46.

[121] Tabas I. Mouse models of apoptosis and efferocytosis. Curr Drug Targets 2008;8 1288-1296.

[122] Thorp E, Li G, Seimon T, Kuriakose G, Ron D, Tabas I. Reduced apoptosis and plaque necrosis in advanced atherosclerotic lesions of $\mathrm{ApoE}^{-/-}$mice lacking CHOP. Cell Metab 2009;9 474-481.

[123] Geng Y, Libby P. Progression of atheroma: a struggle between death and procreation. Arterioscler Thromb Vasc Biol 2002;22 1370-1380.

[124] Kedi X, Ming Y, Yongping W et al. Free cholesterol overloading induced smooth muscle cells death and activated both ER- and mitochondrial-dependent death pathway. Atherosclerosis 2009;207 123-130.

[125] Pedruzzi E, Guichard C, Ollivier V et al NAD(P)H oxidase Nox-4-mediates 7-ketocholesterol-induced endoplasmic reticulum stress and apoptosis in human aortic smooth muscle cells. Mol Cell Biol 2004;24 10703-10717.

[126] Gautier E, Huby T, Witztum J, Ouzilleau B, Miller E, Saint-Charles F, Aucouturier P, Chapman J, Lesnik P. Macrophage apoptosis exerts divergent effects on atherogenesis as a function of lesion stage. Circulation 2009;119(13) 1795-1804.

[127] Kumar S, Boehm J, Lee J. p38 MAP kinases: key signaling molecules as therapeutic targets for inflammatory diseases. Nat Rev Drug Discov. 2003;2 717-726.

[128] Tabas I, Ron D. Integrating the mechanisms of apoptosis induced by endoplasmic reticulum stress. Nat Cell Biol 2011;13(3) 184-190.

[129] Timmins J, Ozcan L, Seimon T, Li G, Malagelada C, Backs J, Backs T, Bassel-Duby R, Olson E, Anderson M, Tabas I. Calcium/calmodulin-dependent protein kinase II links ER stress with Fas and mitochondrial apoptosis pathways. J Clin Invest 2009;119 2925-2941.

[130] Hollien J, Lin J, Stevens N, Walter P, Weissman J. Regulated Ire-dependent decay of messenger RNAs in mammalian cells. J Cell Biol 2009;186 323-331.

[131] Levine B, Sinha S, Kroemer G. Bcl-2 family members. Dual regulators of apoptosis and autophagy. Autophagy 2008;4(5) 600-606.

[132] Cheng W, Hung H, Wang B, Shyu K. The molecular regulation of GADD 153 in apoptosis of cultured vascular smooth muscle cells by cyclic mechanical stretch. Cardiovasc Res 2008;77 551-559.

[133] Li G, Mongillo M, Chin K, Harding H, Ron D, Marks A, Tabas I. Role of ERO1-alphamediated stimulation of inositol 1,4,5-triphosphate receptor activity in endoplasmic reticulum-stress-induced apoptosis. J Cell Biol 2009;186 783-792. 
[134] Timmins J, Ozcan L, Seimon T, Li G, Malagelada C, Backs J, Backs T, Bassel-Duby R, Olson E, Anderson M, Tabas I. Calcium/calmodulin -dependent protein kinase II in ER stress-induced apoptosis. Cell Cycle 2010;9 223-224.

[135] Yoneda T, Imaizumi K, Oono K, Yui D, Gomi F, Katayama T, Tohyama M. Activation of caspase 12, an endoplasmic reticulum (ER) resident caspase, through tumor necrosis factor receptor-associated factor 2 -dependent mechanism in response to ER stress. J Biol Chem 2001;276(17) 13935-13940.

[136] Woo C, Kutzler L, Kimball S, Tabas I. Toll-like receptor activation suppresses ER stress factor CHOP and translation inhibition through activation of eIF2B. Nat Cell Biol 2012;14(2) 192-200.

[137] Hetz C. The unfolded protein response controlling cell fate decisions under ER stress and beyond. Nat Rev Mol Cell Biol 2012;13 89-102.

[138] Treglia A, Turco S, Ulianich L, Ausiello P, Lofrumento D, Nicolardi G, Miele C, Garbi C, Beguinot F, Di Jeso B. Cell fate following ER stress: just a matter of "quo ante" recovery or death?. Histol Histopathol 2012;27 1-12.

[139] Antonetti D, Klein R, Gardner T. Diabetic retinopathy. N Engl J Med 2012;366(13) 1227-1239.

[140] Li J, Wang J, Yu Q, Wang M, Zhang S. Endoplasmic reticulum stress is implicated in retinal inflammation and diabetic retinopathy. FEBS Lett 2009;583(9) 1521-1527.

[141] Li J, Wang J, Zhang S. Preconditioning with endoplasmic reticulum stress mitigates retinal endothelial inflammation via activation of X-box binding protein 1. J Biol Chem 2011;286(6) 4912-4921.

[142] Engin F, Hotamisligil G. Restoring endoplasmic reticulum function by chemical chaperones: an emerging therapeutic approach for metabolic diseases. Diabetes Obes Metab 2010;12 (Suppl2) 108-115.

[143] Ozcan L, Ergin A, Lu A, Chung J, Sarkar S, Nie D, Myers M, Ozcan U. Endoplasmic reticulum stress plays a central role in development of leptin resistance. Cell Metab 2009;9(1) 35-51.

[144] Deniaud A,Sharaf E, Mailier E, Poncet D, Kroemer G, Lemaire C, Brenner C. Endoplasmic reticulum stress induces calcium-dependent permeability transition, mitochondrial outer membrane permeabilization and apoptosis. Oncogene 2008;27(3) 285-299.

[145] Malhotra J, Kaufman R. Endoplasmic reticulum stress and oxidative stress: a vicious cycle or a double-edged sword? Antioxid Redox Signal 2007;9(12) 2277-2293.

[146] Ozcan U, Yilmaz E, Ozcan L, Furuhashi M, Vaillancourt E, Smith R, Gorgun C, Hotamisligil G. Chemical chaperones reduce ER stress and restore glucose homeostasis in a mouse model of type 2 diabetes. Science 2006;313(5790) 1137-1140. 
[147] Lee A, Heidtman K, Hotamisligil G, et al Dual and opposing roles of the unfolded protein response regulated by IRE1alpha and XBP1 in proinsulin processing and insulin secretion. Proc Natl Acad Sci USA 2011;108(21) 8885-8890.

[148] Chen Z, Zhao B, Tang X, Li W, Zhu L, Tang C, Du J, Jin H. Hydrogen sulfide regulates vascular endoplasmic reticulum stress in apolipoprotein $\mathrm{E}$ knockout mice. Chin Med J 2011; 124(21): 3460-3467

[149] Philippova M, Ivanov M, Joshi M, Kyriakakis E, Rupp K, Afonyushikin T, Bochov V, Erne P, Resink T. Identification of proteins associating with glycosylphoshatidylinositol-anchored T-cadherin on the surface of vascular endothelial cells: role for Grp78/BiP in T-cadherin-dependent cell survival. Mol Cell Biol 2008;28(12) 4004-4017.

[150] Kyriakakis E, Philippova M, Joshi M, Pfaff D, Bochov V, Afonyushkin T, Erne P, Resink T. T-cadherin attenuates the PERK branch of the unfolded protein response and protects vascular endothelial cells from endoplasmic reticulum stress-induced apoptosis. Cellular Signalling 2010;22(9) 1308-1316.

[151] Nakka V, Gusain A, Raghubir R. Endoplasmic reticulum stress plays critical role in brain damage after cerebral ischemia/reperfusion in rats. Neurotox Res 2010;17(2) 189-202.

[152] Sanson M, Augè N, Vindis C, Muller C, Bando Y, Thiers J, Marachet M, Zarkovic K, Sawa Y, Salvayre R, Negre-Salvayre A. Oxidized low-density lipoproteins trigger endoplasmic reticulum stress in vascular cells: prevention by oxygen-regulated protein 150 expression. Circ Res 2009;104(3) 328-336.

[153] Muller C, Salvayre R, Negre-Salvayre A, Vindis C. HDLs inhibit endoplasmic reticulum stress and autophagic response induced by oxidized LDLs. Cell Death Differ $2011 ; 18(5)$ 817-828.

[154] Muller C, Salvayre R, Negre-Salvayre A, Vindis C. Oxidized LDLs trigger endoplasmic reticulum stress and autophagy. Prevention by HDLs. Autophagy 2011;7(5) 541-543.

[155] Matsushita E, Asai N, Enomoto A, Kawamoto Y, Kato T, Mii S, Maeda K, Shibata R, et al. Protective role of Gipie, a Girdin family protein, in endoplasmic reticulum stress responses in endothelial cells. Mol Biol Cell 2011;22(6) 736-747. 